\title{
Selective oxidation of glycerol to lactic acid over activated carbon supported Pt catalyst in alkaline solution
}

\author{
Chen Zhang a,c, Tao Wang a,\#, Xiao Liu a,c, Yunjie Ding a,b,* \\ a Dalian National Laboratory for Clean Energy, Dalian Institute of Chemical Physics, Chinese Academy of Sciences, Dalian 116023, Liaoning, China \\ b State Key Laboratory of Catalysis, Dalian Institute of Chemical Physics, Chinese Academy of Sciences, Dalian 116023, Liaoning, China \\ c University of Chinese Academy of Sciences, Beijing 100049, China
}

\section{A R T I C L E I N F O}

Article history:

Received 6 January 2016

Accepted 30 January 2016

Published 5 April 2016

\section{Keywords:}

Glycerol

Lactic acid

Platinum

Activated carbon

Oxidation

Base type

\begin{abstract}
A B S T R A C T
$\mathrm{Pt} /$ activated carbon (Pt/AC) catalyst combined with base works efficiently for lactic acid production from glycerol under mild conditions. Base type $\left(\mathrm{LiOH}, \mathrm{NaOH}, \mathrm{KOH}\right.$, or $\left.\mathrm{Ba}(\mathrm{OH})_{2}\right)$ and base/glycerol molar ratio significantly affected the catalytic performance. The corresponding lactic acid selectivity was in the order of $\mathrm{LiOH}>\mathrm{NaOH}>\mathrm{KOH}>\mathrm{Ba}(\mathrm{OH})_{2}$. An increase in LiOH/glycerol molar ratio elevated the glycerol conversion and lactic acid selectivity to some degree, but excess LiOH inhibited the transformation of glycerol to lactic acid. In the presence of Pt/AC catalyst, the maximum selectivity of lactic acid was $69.3 \%$ at a glycerol conversion of $100 \%$ after $6 \mathrm{~h}$ at $90{ }^{\circ} \mathrm{C}$, with a Li$\mathrm{OH} /$ glycerol molar ratio of 1.5 . The Pt/AC catalyst was recycled five times and was found to exhibit slightly decreased glycerol conversion and stable lactic acid selectivity. In addition, the experimental results indicated that reaction intermediate dihydroxyacetone was more favorable as the starting reagent for lactic acid formation than glyceraldehyde. However, the Pt/AC catalyst had adverse effects on the intermediate transformation to lactic acid, because it favored the catalytic oxidation of them to glyceric acid.
\end{abstract}

(c) 2016, Dalian Institute of Chemical Physics, Chinese Academy of Sciences. Published by Elsevier B.V. All rights reserved.

\section{Introduction}

Biofuel synthesis via transesterification of plant or animal oil has become a promising alternative route for sustainable energy production, and also produces glycerol as a major by-product during the manufacturing process. Therefore, the transformation of glycerol into value-added chemicals is vital to the overall competitiveness of the biofuel industry $[1,2]$. The structural characteristic of triple hydroxyl groups makes glycerol an excellent chemical feedstock for the synthesis of versatile high-value derivatives, such as lactic acid (LA), glyceric acid (GLYA), and 1,3-propanediol [3-6]. In particular, LA is an im- portant building block chemical that is widely used in the food, cosmetics, and pharmaceutical industries. Notably, polylactic acid has the potential to replace conventional oil-based polyethylene terephthalate (PET) plastics because of its biodegradability and biocompatibility [7]. It is estimated that the worldwide demand for LA will reach $600 \mathrm{kt}$ in 2020 [8]. At present, LA is mainly produced by fermentation from carbohydrates; however, this process is time-consuming and involves complex separation steps [9]. As a result, the chemical transformation of glycerol to LA is attracting extensive efforts from the academic and industrial communities.

The chemical production of LA from glycerol has been in-

\footnotetext{
* Corresponding author. Tel/Fax: +86-411-84379143; E-mail: dyj@dicp.ac.cn

\# Corresponding author. Tel/Fax: +86-411-84379143; E-mail: wangtao@dicp.ac.cn

This work was supported by the National Natural Science Foundation of China (21176236).

DOI: 10.1016/S1872-2067(15)61055-5 | http://www.sciencedirect.com/science/journal/18722067 | Chin. J. Catal., Vol. 37, No. 4, April 2016
} 
vestigated through different approaches, including hydrothermal reactions [10-12], hydrogenolysis methods [13,14] and catalytic selective aerobic oxidations $[3,15,16]$. Kishida et al. [10] reported hydrothermal decomposition of glycerol to LA in the presence of $\mathrm{NaOH}$ at $300^{\circ} \mathrm{C}$, where the LA molar yield could reach $90 \%$. Meanwhile, the catalytic hydrogenolysis of glycerol to LA has been explored over $\mathrm{Ru}$ and Pt catalysts at $200{ }^{\circ} \mathrm{C}$ under $4 \mathrm{MPa} \mathrm{H}_{2}$ in basic solutions, achieving yields no higher than 58\% [13]. Unfortunately, severe reaction conditions (including high temperature and pressure) have been major concerns in scaling up the reaction. Thus, the selective oxidation of glycerol to lactic acid in basic aqueous solution is still attractive under mild reaction conditions. Shen et al. [3] first reported a one-pot $\mathrm{Au}-\mathrm{Pt} / \mathrm{TiO}_{2}$-catalyzed aerobic oxidation of glycerol at $90{ }^{\circ} \mathrm{C}$ in $\mathrm{NaOH}$ with a LA yield of around $86 \%$. Similar results have been achieved on $\mathrm{Au} / \mathrm{CeO}_{2}$ and $\mathrm{Pt}-\mathrm{Au} / \mathrm{CeO}_{2}$ catalysts under basic conditions $[15,16]$.

Generally, the production of LA from glycerol oxidation over supported noble metal catalysts is assisted by concentrated $\mathrm{NaOH}$ solution, typically with a $\mathrm{NaOH}$ to glycerol molar ratio of 4 [16-18]. However, to date, there have been few reports on glycerol oxidation to lactic acid in different alkaline solutions. In an $\mathrm{Au}$-Pt/C-catalyzed 1,2-propanediol oxidation process, Ryabenkova et al. [19] reported that the presence of $\mathrm{LiOH}$ afforded the highest lactate yield amongst the different alkalis ( $\mathrm{LiOH}, \mathrm{NaOH}, \mathrm{KOH}, \mathrm{CsOH}$, and $\mathrm{RbOH}$ ). Given that each hydroxide alkali possesses a specific ionic radius, their respective alkali solubility, solution viscosity, and oxygen solubility may affect the catalytic reaction behavior [20,21].

Carbon materials have been widely used as supports in heterogeneous catalysis because of their unique advantages, including large specific surface area, stability in both acidic and basic solutions, and easy recovery of the noble metal. Until recently, carbon-supported catalysts were investigated to produce LA from glycerol oxidation; however, GLYA was generated as the major product. For example, Chornaja et al. [17] and Ketchie et al. [18] reported less than 5\% LA selectivity over $\mathrm{Pd} / \mathrm{C}$ and $\mathrm{Au} / \mathrm{C}$ catalysts, respectively. Heeres et al. [16] also investigated the conversion of glycerol to LA over $\mathrm{Au} / \mathrm{C}$ catalysts and obtained $27 \%$ LA selectivity, which was the highest yield on carbon-supported catalysts at the time. Therefore, further investigation of carbon-supported catalyst is attractive from both academic and industrial perspectives.

Herein, we report a study on glycerol oxidation to produce LA over Pt/activated carbon (Pt/AC) catalyst in alkaline aqueous solution under $\mathrm{O}_{2}$ at atmospheric pressure. The effects of base type $\left(\mathrm{LiOH}, \mathrm{NaOH}, \mathrm{KOH}\right.$, and $\left.\mathrm{Ba}(\mathrm{OH})_{2}\right)$ and base/glycerol molar ratio on catalytic performance were also investigated. We expect that this work will form the basis of a practical method for LA production from glycerol using AC-supported catalysts.

\section{Experimental}

\subsection{Catalyst preparation}

Pt/AC catalyst was prepared by a deposition-precipitation method [3]. In a typical experiment, $3 \mathrm{~g}$ of AC (Tangshan United Carbon, China) was suspended in $300 \mathrm{~mL}$ of deionized water with vigorous stirring, and $0.03 \mathrm{~g}$ of $\mathrm{Pt}$ as $\mathrm{H}_{2} \mathrm{PtCl}_{6}$ ( $\mathrm{Pt} \geq 38 \%$, Shanghai Jiuyue, China) solution was added. After $0.5 \mathrm{~h}$, an excess amount of $\mathrm{NaBH}_{4}(>98 \%$, Tianjin Hainachuan Science and Technology, China) solution was introduced dropwise. The suspended black solution was stirred for $6 \mathrm{~h}$. Afterward, the black precipitate was filtered and washed with deionized water until $\mathrm{Cl}^{-}$was not detectable with $\mathrm{AgNO}_{3}$ solution. The solid was dried at $120^{\circ} \mathrm{C}$ for $12 \mathrm{~h}$. AC was washed with deionized water to remove surface ash and ground to 100-200 mesh before use.

\subsection{Catalyst characterization}

Metal analysis was carried out by inductively coupled plasma optical emission spectroscopy (ICP-OES) on a Perkin Elmer Optima $7300 \mathrm{DV}$, and showed that the Pt loading of the catalyst was $0.9 \mathrm{wt} \%$ (designed loading was $1 \mathrm{wt} \%$ ). The glycerol/Pt molar ratio was calculated based on the $0.9 \mathrm{wt} \%$ loading. Physical adsorption was carried out on a Quantachrome Autosorb-1 instrument. The Brunauer-Emmett-Teller (BET) method was used to calculate the specific surface areas. The $t$-plot method was applied to calculate the external and micro surface areas. Total pore volume was calculated based on the amount of nitrogen adsorbed at a relative pressure $\left(p / p_{0}\right)$ of 0.99 . Before the test, samples were outgassed at $250{ }^{\circ} \mathrm{C}$ for $12 \mathrm{~h}$. Transmission electron microscopy (TEM) was conducted with a JEM-2100 electron microscope operating at $200 \mathrm{kV}$. The metal particle size distribution was calculated by counting approximately 140 particles in TEM images. CO pulse chemisorption was performed on a 150-mg sample in a quartz U-tube on an Altamira Instruments AMI-300 with a thermal conductivity detection (TCD) device and an OmniStar GSD 320 mass spectrometer. After $10 \% \mathrm{H}_{2} / \mathrm{Ar}$ reduction at $200{ }^{\circ} \mathrm{C}$ for $1 \mathrm{~h}$ and Ar post flush, $10 \% \mathrm{CO} / \mathrm{He}$ pulse chemisorption was initiated at $30{ }^{\circ} \mathrm{C}$. A CO/Pt stoichiometry of 1 was used for calculations [22].

\subsection{Glycerol oxidation reaction}

The glycerol oxidation reaction was carried out in a three-neck flask (100 $\mathrm{mL})$ at atmospheric pressure in an oil bath. A known amount of base and catalyst $(0.25 \mathrm{~g})$ were added into glycerol solution ( $25 \mathrm{~g}, 10 \mathrm{wt} \%$ ). When the solution temperature stabilized, $\mathrm{O}_{2}$ flow was initiated at $100 \mathrm{~mL} / \mathrm{min}$ with magnetic stirring at $800 \mathrm{r} / \mathrm{min}$. After the reaction, the aqueous solution was filtered, neutralized with $\mathrm{H}_{2} \mathrm{SO}_{4}$ aqueous solution, and diluted with deionized water. The products were analyzed by high-performance liquid chromatography (HPLC) on an Agilent 1100 instrument equipped with a refractive index detector (RID). The analysis used an Alltech OA-1000 column with a separation temperature of $80^{\circ} \mathrm{C} . \mathrm{H}_{2} \mathrm{SO}_{4}$ aqueous solution $(0.005 \mathrm{~mol} / \mathrm{L})$ was used as the mobile phase at a flow rate of $0.5 \mathrm{~mL} / \mathrm{min}$. All products were identified by comparing retention times with those of pure materials; quantification was by the external standard method. Glycerol conversion and liquid product selectivity were calculated according to the literature with the carbon balance generally more than $90 \%$ unless oth- 
erwise noted [23]. The spent catalyst was separated, washed thoroughly with deionized water, and dried before use in recycling experiments.

\section{Results and discussion}

\subsection{Effects of Pt/AC and NaOH on glycerol oxidation to lactic} acid

The Pt/AC-catalyzed glycerol oxidation was conducted and the results are summarized in Table 1 . In all reactions, the products were obtained as salts, but for simplicity and comparison they were marked as the acid forms. The coexistence of $\mathrm{Pt} / \mathrm{AC}$ and $\mathrm{NaOH}$ led to LA production, giving 58.5\% glycerol conversion and $44.9 \%$ LA selectivity. By-products were also detected, including GLYA, tartronic acid (TA), glycolic acid (GA), oxalic acid (OA), acetic acid (AA), and formic acid (FA). Reaction intermediates such as glyceraldehyde (GlA), dihydroxyacetone (DHA), and pyruvaldehyde (PyA), if at all present, could not be detected under the reaction conditions.

For a better understanding of the roles that the metal catalyst and base played in the oxidation reaction, single variable analyses were performed without Pt/AC or base (Table 1). In the absence of Pt/AC catalyst, $\mathrm{NaOH}$ converted a trace amount of glycerol to form GA (33.4\%) as the main product, together with $17.5 \%$ selectivity for LA and $24.6 \%$ selectivity for GLYA. In a base-free environment, glycerol conversion was $18.6 \%$ with 86.3\% selectivity for GLYA over Pt/AC catalyst, and the target LA was not detected. The results demonstrate that Pt/AC catalyst plays a decisive role in glycerol activation, probably because the primary H-elimination occurs much more easily on a metallic catalyst than in basic solution alone [24]. The role of the base is to increase the rate of glycerol oxidation by aiding the initial deprotonation over the Pt catalyst, and favorably shift the equilibrium by forming salt products [24]. Meanwhile, the base also favors the intramolecular Cannizzaro rearrangement over LA production $[3,12]$. This suggests that the collaboration of the metal catalyst and base is indispensable for LA production from glycerol oxidation, which is in line with Liu's report [25].

The glycerol oxidation pathways that lead to LA and GLYA are different (Scheme 1). Glycerol is first dehydrogenated to GIA and DHA intermediates by the coordination of Pt/AC and base. They then undergo either base-catalyzed dehydration together with intramolecular Cannizzaro rearrangement to LA, or further metal-catalyzed oxidation to GLYA, TA, and C-C cleavage products such as GA or FA $[3,16,26]$. However, the mechanism for the transformation of intermediates GlA and

Table 1

Comparison of catalyst and base performances in glycerol oxidation.

\begin{tabular}{lccccccccc}
\hline \multirow{2}{*}{ Catalyst } & $n_{\mathrm{NaOH}} /$ & Conversion & \multicolumn{6}{c}{ Selectivity (\%) } \\
\cline { 5 - 9 } & $n_{\text {glycerol }}$ & $(\%)$ & LA & GLYA & TA & GA & OA & AA & FA \\
\hline Pt/AC & 4 & 58.5 & 44.9 & 18.4 & 7.9 & 14.1 & 1.6 & 2.1 & 11.0 \\
None & 4 & 5.9 & 17.5 & 24.6 & 0 & 33.4 & 0 & 4.0 & 20.5 \\
Pt/AC & None & 18.6 & 0 & 86.3 & 0.1 & 13.4 & 0.1 & 0.1 & 0 \\
\hline
\end{tabular}

Reaction conditions: $t=90^{\circ} \mathrm{C}, p=0.1 \mathrm{MPa}, 6 \mathrm{~h}, F_{02}=100 \mathrm{~mL} / \mathrm{min}$, stirring speed $=800 \mathrm{r} / \mathrm{min}, n_{\text {glycerol }} / n_{\mathrm{Pt}}=2400$.

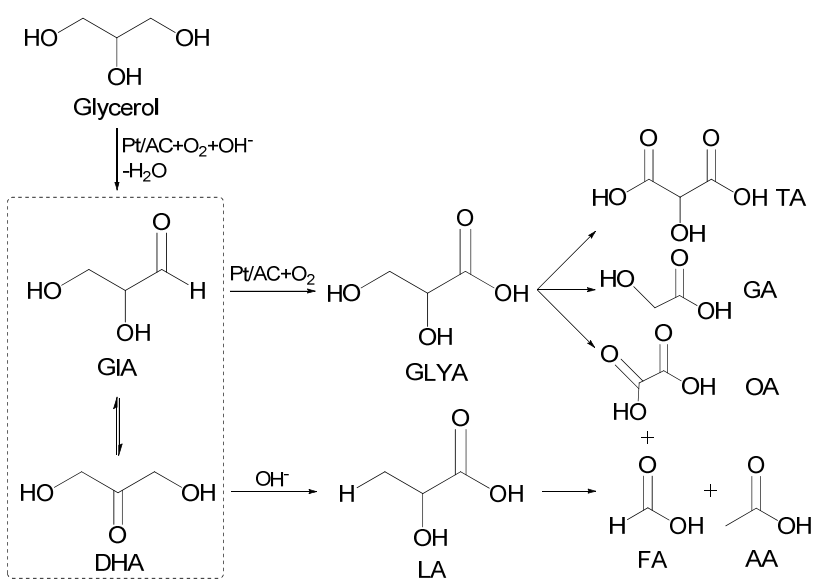

Scheme 1. Proposed reaction pathway for glycerol conversion to lactic acid and by-products on Pt/AC.

DHA to LA or GLYA remains unclear. Their respective selectivity toward LA may provide useful information in the design of an improved catalyst system.

To gain insight into the formation pathway for LA and GLYA from GlA or DHA, a series of experiments were performed in $\mathrm{NaOH}$ aqueous solution under an $\mathrm{O}_{2}$ atmosphere with either GlA or DHA as the starting reagent. At 5 min of reaction time, GlA or DHA had disappeared completely and the main products were LA and GLYA, with small amounts of other products (TA, GA, OA, and FA; not shown here). Figure 1 (filled symbols) depicts the plot of LA/GLYA molar ratio as a function of reaction time on stream in the presence of the base but without the metal catalyst. DHA reaction showed higher LA/GLYA molar ratios than that of GlA reaction, indicating that DHA as the substrate was relatively more favorable than GlA to form LA. In general, DHA can produce LA at low temperatures of 15-140 ${ }^{\circ} \mathrm{C}$; however, GlA generates LA at higher temperatures of 200-300 ${ }^{\circ} \mathrm{C}[13,27-29]$. The latter reaction probably needs to overcome a high energy barrier because the formation of LA is favored from GlA at higher temperature. Another possibility may be related to the transformation rate, which could be in-

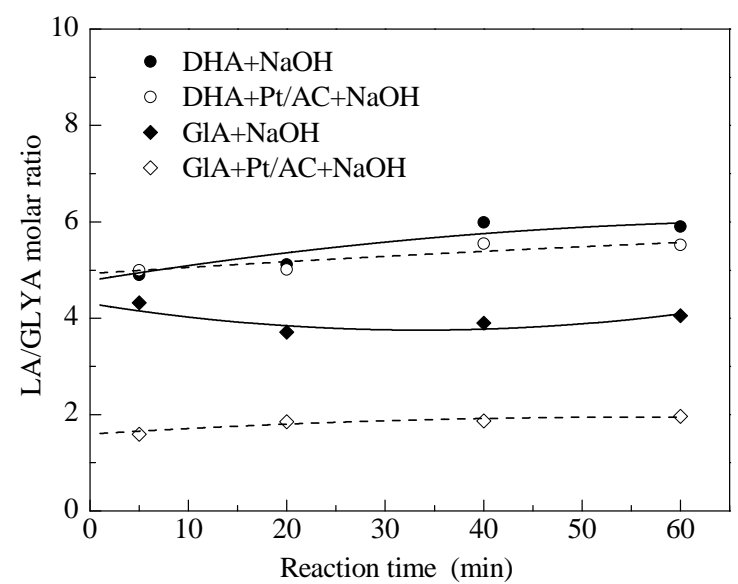

Fig. 1. LA/GLYA molar ratio variation with or without $\mathrm{Pt} / \mathrm{AC}$ in $\mathrm{NaOH}$ solution. Reaction conditions: substrate $=0.1 \mathrm{~mol} / \mathrm{L}$ DHA or GlA, $\mathrm{NaOH} /$ substrate molar ratio $=4: 1, m_{\mathrm{Pt} / \mathrm{AC}} / m_{\text {substrate solution }}=1: 1000$, other conditions same as Table 1 . 
ferred from Lookhart's observation that DHA was dehydrated much faster than GIA [30]. Furthermore, the LA/GLYA molar ratio was almost constant as reaction time increased, which indicates that the further oxidation of GLYA to TA and C-C spilling of products occurred relatively slowly, and thus maintained a stable LA/GLYA ratio.

Figure 1 (open symbols) shows LA/GLYA molar ratio variations in $\mathrm{NaOH}$ aqueous solution with Pt/AC catalyst. For DHA reaction, the LA/GLYA molar ratio dropped slightly from 5.5 to 5.3. In contrast, for GlA as substrate, the LA/GLYA ratio decreased remarkably from 4 to less than 2. Obviously, when Pt/AC was added, LA formation was inhibited and GLYA production was facilitated regardless of GlA or DHA as substrate. Interestingly, $\mathrm{Pt} / \mathrm{AC}$ catalyst accelerated the transformation of GIA to GLYA over that of DHA. Chornaja et al. [17] also reported that the rate of GlA oxidation to GLYA was higher than GIA transformation to $\mathrm{LA}$ using a $\mathrm{Pd} / \mathrm{Al}_{2} \mathrm{O}_{3}$ catalyst in alkaline aqueous solution. Thus, we depict the possible pathway for LA production as shown in Scheme 2. DHA is firstly dehydrated to PyA in basic solution, followed by a base-catalyzed rearrangement of PyA to LA, and accompanied with DHA isomerization to GIA and further oxidation to GLYA over Pt/AC catalyst. In other words, DHA may take one step less than GlA toward LA, which may contribute to its better assistance for LA production. Therefore, by careful control of alkaline conditions, a higher DHA/GlA ratio may be achieved, which would facilitate the selectivity to LA.

\subsection{Effect of different hydroxides on glycerol oxidation to lactic acid}

The use of a base is a crucial factor in glycerol oxidation to LA, so we further investigated the effect of alkali type on the performance of glycerol oxidation over Pt/AC catalyst (Table 2). Three alkali-metal hydroxides ( $\mathrm{LiOH}, \mathrm{NaOH}$, and $\mathrm{KOH}$ ) and one alkaline-earth hydroxide $\mathrm{Ba}(\mathrm{OH})_{2}$ were used. Other alkaline-earth hydroxides were not adopted because of their poor solubilities [11,31]. When LiOH was used as the base, the glycerol conversion was $60.4 \%$ and LA selectivity was $60.1 \%$ after $6 \mathrm{~h}$, which was the highest among the four alkalis. When $\mathrm{NaOH}$ was introduced, the glycerol conversion and LA selectivity
Table 2

Glycerol oxidation reaction with different bases over Pt/AC catalyst.

\begin{tabular}{lccccccccr}
\hline \multirow{2}{*}{ Base } & $n_{\text {base }}$ & Conversion & \multicolumn{6}{c}{ Selectivity (\%) } \\
\cline { 5 - 10 } & $n_{\text {glycerol }}$ & $(\%)$ & LA & GLYA & TA & GA & OA & AA & FA \\
\hline $\mathrm{LiOH}$ & 2 & 60.4 & 60.1 & 17.9 & 4.5 & 7.5 & 2.8 & 1.4 & 5.8 \\
$\mathrm{NaOH}$ & 2 & 62.6 & 51.2 & 13.6 & 5.4 & 11.9 & 5.7 & 1.8 & 10.4 \\
$\mathrm{KOH}$ & 2 & 63.4 & 43.3 & 17.1 & 5.8 & 11.3 & 2.8 & 5.0 & 14.7 \\
$\mathrm{Ba}(\mathrm{OH})_{2}$ & 1 & 41.8 & 24.8 & 29.3 & 0.2 & 20.9 & 0.9 & 5.0 & 18.9 \\
\hline
\end{tabular}

Reaction conditions: $t=90^{\circ} \mathrm{C}, p=0.1 \mathrm{MPa}, 6 \mathrm{~h}, F_{02}=100 \mathrm{~mL} / \mathrm{min}$, stirring speed $=800 \mathrm{r} / \mathrm{min}, n_{\text {glycerol }} / n_{\mathrm{Pt}}=2400$.

were $62.6 \%$ and $51.2 \%$, respectively. In $\mathrm{KOH}$ aqueous solution, the glycerol conversion was similar to $\mathrm{LiOH}$ and $\mathrm{NaOH}$, but LA selectivity decreased to $43.3 \%$. $\mathrm{Ba}(\mathrm{OH})_{2}$ showed much lower glycerol conversion (41.8\%) and LA selectivity (24.8\%). The former three hydroxides have lower electric charge, lower molecular weight, and smaller structure than $\mathrm{Ba}(\mathrm{OH})_{2}$, which might enable them to dissociate and move rapidly in the reaction solution, providing dissociated hydroxyl ions to promote the reaction networks. In contrast, the higher electric charge and larger ionic radius of $\mathrm{Ba}(\mathrm{OH})_{2}$ might favor the undesirable LA decomposition to $\mathrm{C}_{1}$ and $\mathrm{C}_{2}$ products [11]. Therefore, alkali-metal hydroxides were a better choice than alkaline-earth hydroxide $\mathrm{Ba}(\mathrm{OH})_{2}$ for LA production.

Although the three alkali-metal hydroxides showed similar glycerol conversions, their LA selectivities were obviously different in the order of $\mathrm{KOH}<\mathrm{NaOH}<\mathrm{LiOH}$ (Table 2). This suggests a mechanism whereby the metal ion exerts significant influence on the oxidation behavior. Changes in the metal ion radius causes several physicochemical properties, such as solution alkalinity, solubility of oxygen, and viscosity [21,32].

In Group IA, alkalinity is positively related with radius length (Table 3). The stronger alkalinity might improve the deprotonation process during the glycerol oxidation reaction. Thus, their glycerol conversions exhibited the same order as their alkalinities and radii. The highest LA selectivity was obtained in $\mathrm{LiOH}$ aqueous medium, which might be related to the oxygen solubility in solution. We tested the oxygen solubility in basic reaction solution and found that $\mathrm{LiOH}$ solution dissolved more oxygen than $\mathrm{NaOH}$ and $\mathrm{KOH}$ (Table 3), which was consistent with Battino's report [33]. According to Davis et al. [34], the role of $\mathrm{O}_{2}$ is to assist the regeneration of hydroxide ions via

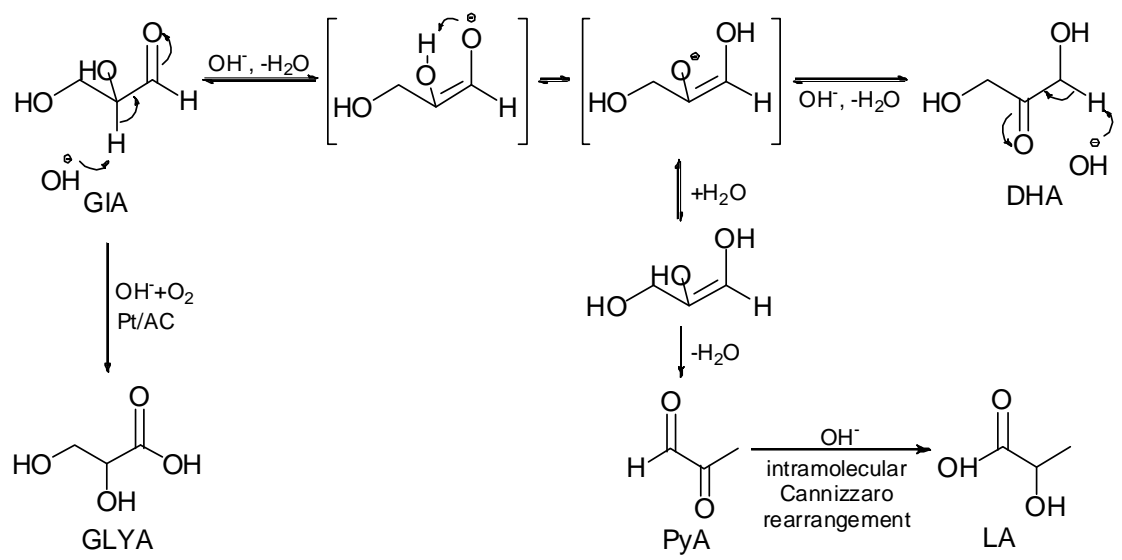

Scheme 2. Possible DHA and GlA conversion pathway toward LA and GLYA. 
Table 3

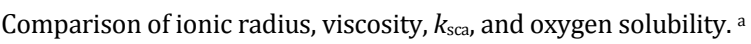

\begin{tabular}{lcccc}
\hline Base & $\begin{array}{c}\text { Ionic radius } \\
(\mathrm{pm})\end{array}$ & $\begin{array}{c}\text { Viscosity }^{\mathrm{c}} \\
(\mathrm{mPa} \cdot \mathrm{s})\end{array}$ & $\begin{array}{c}k_{\text {sca }^{\mathrm{d}}} \\
(\mathrm{L} / \mathrm{mol})\end{array}$ & $\begin{array}{c}\text { Oxygen solubility }^{\mathrm{e}} \\
(\mathrm{mg} / \mathrm{L})\end{array}$ \\
\hline $\mathrm{LiOH}$ & 76 & 1.66 & 0.091 & 30.1 \\
$\mathrm{NaOH}$ & 102 & 1.50 & 0.181 & 29.1 \\
$\mathrm{KOH}$ & 138 & 1.16 & 0.176 & 28.8 \\
\hline
\end{tabular}

a Because water is in absolute majority (90 wt\%) in reaction solution, all the physicochemical parameters are considered valid.

b Theoretical 6-coordinate ionic radius. Variation trend at other coordinate numbers is similar [32].

c Calculated by linear interpolation on literature data between 0.7 and 4 $\mathrm{mol} / \mathrm{L}$ at $25^{\circ} \mathrm{C}[20]$.

d The oxygen solubility could be represented as $k_{\text {sca }}$ (i.e., the Setschenow salt effect parameter); these data were acquired for base concentrations of $0.8-1.2 \mathrm{~mol} / \mathrm{L}$ [35].

e Data obtained by iodometric method (Chinese GB 7489-87, totally equivalent to ISO 5813:1983) after 20 min oxygen bubbling and 2 min standing at room temperature $\left(20^{\circ} \mathrm{C}\right)$ with base/glycerol ratio of 0.5 . Other conditions identical to those described in Table 2 except that no catalyst was added to avoid disturbance.

the catalytic decomposition of a peroxide intermediate over Pt sites. When more oxygen is dissolved, the hydroxide ions regenerate faster and promote LA production in the presence of $\mathrm{Pt} / \mathrm{AC}$ catalyst. Besides, it is possible that a smaller metal ion radius might favor the glycerol dehydrogenation toward more DHA, thus enhancing LA formation, and this proposal still requires verification.

\subsection{Effect of LiOH/glycerol molar ratio on glycerol oxidation to lactic acid}

Further optimization reactions were performed in $\mathrm{LiOH}$ medium at different $\mathrm{LiOH} /$ glycerol molar ratios and the results are shown in Table 4. Before reaching a molar ratio of 1.5 , both glycerol conversion and LA selectivity were enhanced with elevated $\mathrm{LiOH}$ concentration, and the maximum LA selectivity was $69.3 \%$ at $100 \%$ glycerol conversion. However, further elevation of the $\mathrm{LiOH} /$ glycerol molar ratio caused a decrease in both reaction activity and LA selectivity. Glycerol conversion dropped significantly to $69.3 \%$ at a molar ratio of 1.75 and further dropped to $60.4 \%$ at a ratio of 2 . The LA selectivity gradually decreased from $69.3 \%$ to $60.1 \%$ when the $\mathrm{LiOH} /$ glycerol molar ratio increased from 1.5 to 2.0. This indicates that the optimum LiOH/glycerol molar ratio was 1.5 under our reaction conditions, with relatively high LA selectivity at full glycerol conversion.

\section{Table 4}

Glycerol oxidation reaction at different LiOH/glycerol molar ratios.

\begin{tabular}{|c|c|c|c|c|c|c|c|c|}
\hline \multirow{2}{*}{$\begin{array}{l}\mathrm{LiOH} / \text { glycerol } \\
\text { molar ratio }\end{array}$} & \multirow{2}{*}{$\begin{array}{c}\text { Conversion } \\
(\%)\end{array}$} & \multicolumn{7}{|c|}{ Selectivity (\%) } \\
\hline & & LA & GLYA & $\mathrm{TA}$ & GA & $\mathrm{OA}$ & $\mathrm{AA}$ & FA \\
\hline 1.0 & 73.6 & 52.6 & 17.1 & 5.0 & 13.5 & 3.2 & 3.0 & 5.6 \\
\hline 1.25 & 89.7 & 56.7 & 15.2 & 6.1 & 11.1 & 3.4 & 2.9 & 4.6 \\
\hline 1.5 & 100 & 69.3 & 8.0 & 9.4 & 5.9 & 2.5 & 1.4 & 3.5 \\
\hline 1.75 & 69.3 & 61.8 & 15.8 & 4.4 & 8.0 & 2.6 & 1.5 & 5.9 \\
\hline 2.0 & 60.4 & 60.1 & 17.9 & 4.5 & 7.5 & 2.8 & 1.4 & 5.8 \\
\hline
\end{tabular}

Reaction conditions: $t=90^{\circ} \mathrm{C}, p=0.1 \mathrm{MPa}, 6 \mathrm{~h}, F_{02}=100 \mathrm{~mL} / \mathrm{min}$, stirring speed $=800 \mathrm{r} / \mathrm{min}, n_{\text {glycerol }} / n_{\mathrm{Pt}}=2400$.
At low $\mathrm{LiOH} /$ glycerol molar ratios, the reaction products were almost acidic, indicating that the amount of base might be insufficient to aid the dehydrogenation reaction from the hydroxyl groups of glycerol and to further catalyze the Cannizzaro rearrangement to LA formation. Such an insufficiency would suppress both glycerol conversion and LA selectivity. When more LiOH was added, the dehydrogenation reaction proceeded faster toward intermediates GIA and DHA. Simultaneously, the base-catalyzed rearrangement of intermediates was promoted to generate more LA.

When LiOH/glycerol molar ratios were above 1.5 , the glycerol conversion dropped drastically. This may be a result of declines in mass transfer rate and oxygen solubility, which were caused by increased base ratio and viscosity $[20,35]$. The oxygen diffusivity and oxygen solubility decline rapidly owing to the LiOH concentration increase. Thus, the oxidation dehydrogenation on the Pt/AC catalyst may be affected, leading to lower glycerol conversion and corresponding GlA or DHA intermediates. The LA selectivity also dropped because the extra base may facilitate glycerol transformation to GlA, which is likely to form more GLYA in the presence of Pt/AC.

\subsection{Effect of reaction time on glycerol oxidation to lactic acid}

Figure 2 shows the glycerol conversion and variation in product selectivity as a function of reaction time at the optimized LiOH/glycerol ratio of 1.5. Glycerol was converted completely within $6 \mathrm{~h}$. There was a near-linear increase in glycerol conversion, which implied that Pt/AC maintained activity during the oxidation reaction. Furthermore, LA had the highest selectivity at any glycerol conversion among the reaction products, indicating that LA was the dominant product. The LA selectivity reached a maximum (69.3\%) after $6 \mathrm{~h}$ and then decreased slightly. The AA selectivity increased slightly, implying that LA was not stable and might decompose to AA. It was noted that the selectivity of GLYA decreased remarkably because of the consecutive oxidation of GLYA to TA and OA.

The stability of the Pt/AC catalyst was tested in a recycling experiment for five runs. As shown in Fig. 3, the glycerol con-

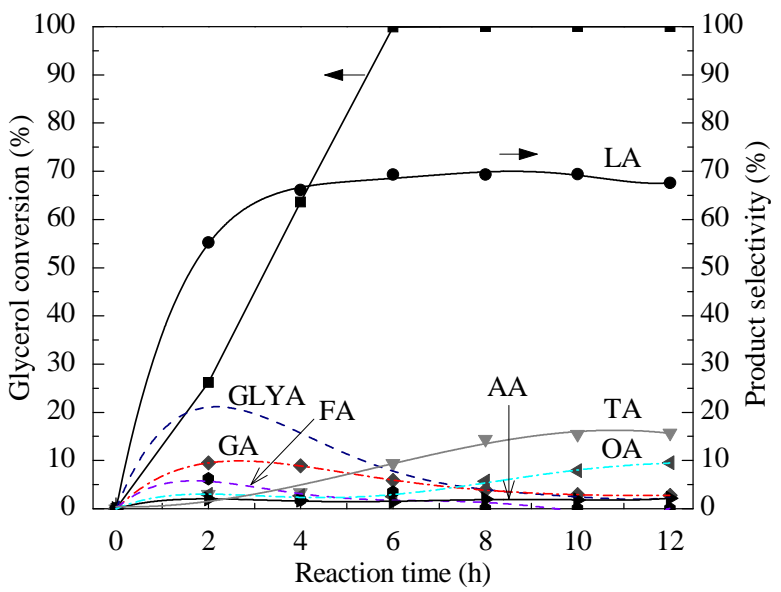

Fig. 2. Variation of the glycerol conversion and product selectivity with time on stream. Reaction conditions: $t=90^{\circ} \mathrm{C}, p=0.1 \mathrm{MPa}, F_{02}=100$ $\mathrm{mL} / \mathrm{min}$, stirring speed $=800 \mathrm{r} / \mathrm{min}, n_{\mathrm{glycerol}} / n_{\mathrm{Pt}}=2400$. 


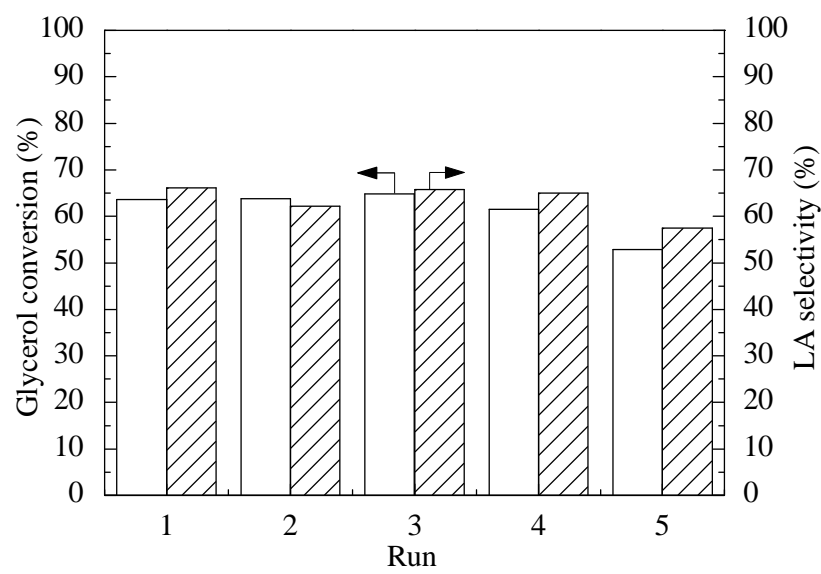

Fig. 3. Recycling tests of Pt/AC catalyst for 4-h glycerol oxidation reaction. Reaction conditions: $t=90{ }^{\circ} \mathrm{C}, p=0.1 \mathrm{MPa}, F_{02}=100 \mathrm{~mL} / \mathrm{min}$, stirring speed $=800 \mathrm{r} / \mathrm{min}, n_{\mathrm{glyc} c r o l} / n_{\mathrm{Pt}}=2400$.

version decreased from $63.6 \%$ to $52.9 \%$ after five runs, but the selectivity of LA was still around $60 \%$. Metal analysis by ICP-OES revealed that Pt leaching was below the limit of detection and negligible. However, the specific surface area of the $\mathrm{Pt} / \mathrm{AC}$ catalyst decreased after five runs (Table 5), which might be ascribed to chelation of product on the catalyst surface, which would prevent the glycerol from accessing the Pt active sites [36]. The pore size distribution based on the NL-DFT method also confirmed the possibility of reactant blockage because the number of pores around $1.9 \mathrm{~nm}$ decreased after reaction (Fig. 4). In addition, the average particle size of Pt increased from 4.4 to $5.5 \mathrm{~nm}$ after five runs (Fig. 5). CO pulse

\section{Table 5}

The specific surface areas and total pore volumes of fresh and spent Pt/AC catalysts.

\begin{tabular}{lcccc}
\hline Catalyst & $S_{\mathrm{BET}}{ }^{\mathrm{a}}\left(\mathrm{m}^{2} / \mathrm{g}\right)$ & $S_{\text {macro }}{ }^{\mathrm{b}}\left(\mathrm{m}^{2} / \mathrm{g}\right)$ & $S_{\text {micro }}\left(\mathrm{m}^{2} / \mathrm{g}\right)$ & $V_{\text {total }^{\mathrm{c}}}\left(\mathrm{cm}^{3} / \mathrm{g}\right)$ \\
\hline Fresh & 970.8 & 278.7 & 692.1 & 0.65 \\
Spent & 687.0 & 221.4 & 465.6 & 0.54
\end{tabular}

a Calculated by the BET method.

b Calculated by the $t$-plot method.

c Calculated based on the amount of nitrogen adsorbed at a relative pressure $\left(p / p_{0}\right)$ of 0.99 .

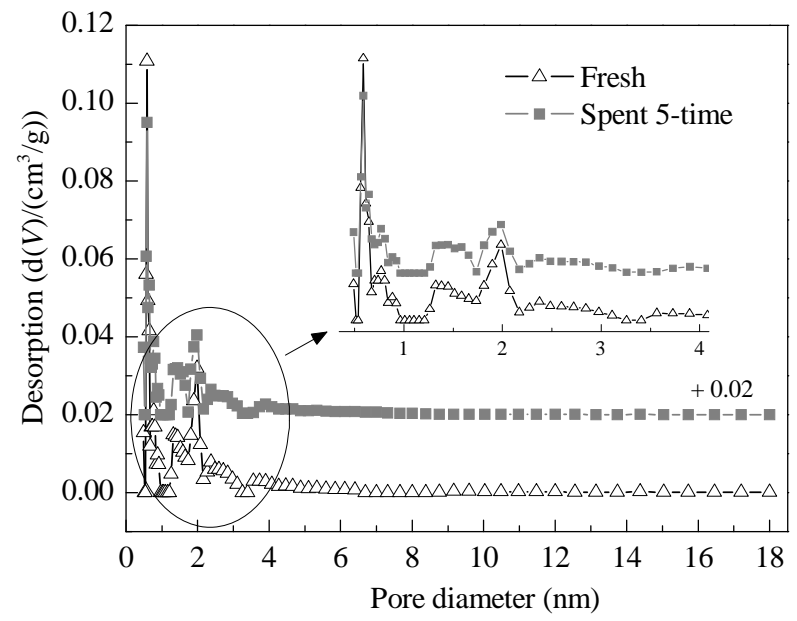

Fig. 4. Pore size distributions of fresh and spent $\mathrm{Pt} / \mathrm{AC}$ catalysts.
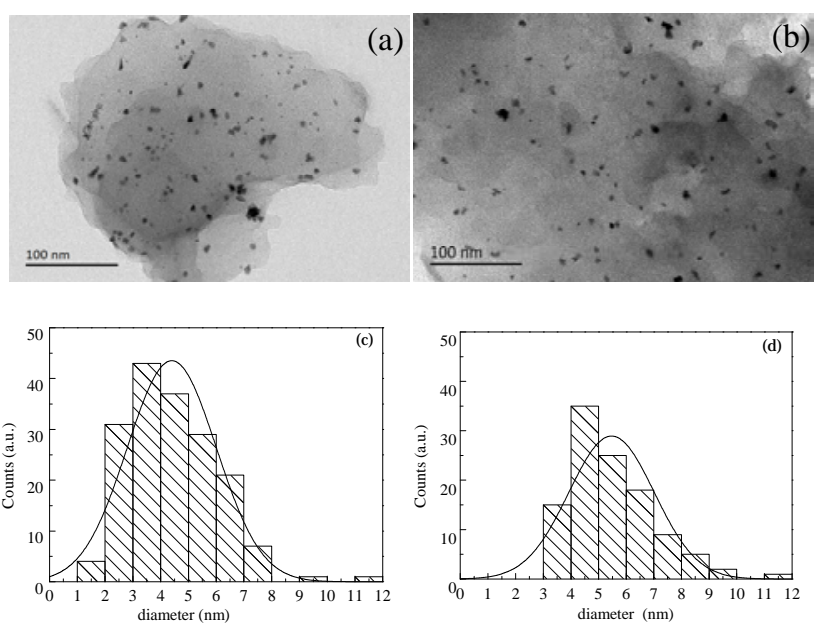

Fig. 5. TEM images of (a) fresh and (b) spent 5-time Pt/AC catalysts; $\mathrm{Pt}$ particle size distributions of (c) fresh and (d) spent 5-time Pt/AC catalysts.

chemisorption of the fresh and spent catalyst also confirmed the slight agglomeration of $\mathrm{Pt}$, with the average particle size increasing from 7.1 to $11.7 \mathrm{~nm}$; Pt dispersion declined from $16.8 \%$ to $10.2 \%$, which may influence the catalyst activity to some degree [37]. Further detailed investigation is necessary to elucidate the deactivation mechanism.

\section{Conclusions}

Lactic acid was prepared as the major product by treatment of glycerol in alkaline aqueous solution in the presence of a $\mathrm{Pt} / \mathrm{AC}$ catalyst. The promotion effect of $\mathrm{LiOH}$ was stronger than the other bases $\left(\mathrm{NaOH}, \mathrm{KOH}\right.$ and $\left.\mathrm{Ba}(\mathrm{OH})_{2}\right)$ in terms of glycerol conversion to LA. Reaction intermediate DHA was more favorable as the starting reagent for LA formation than GlA, but the $\mathrm{Pt} / \mathrm{AC}$ catalyst accelerated further oxidation of DHA and GIA to GLYA. In addition, the Pt/AC catalyst retained high activity and LA selectivity after five runs in a catalyst recycling experiment.

\section{References}

[1] B. Katryniok, H. Kimura, E. Skrzyńska, J. S. Girardon, P. Fongarland, M. Capron, R. Ducoulombier, N. Mimura, S. Paul, F. Dumeignil, Green Chem., 2011, 13, 1960-1979.

[2] C. H. Zhou, J. N. Beltramini, Y. X. Fan, G. Q. Lu, Chem. Soc. Rev., 2008, 37, 527-549.

[3] Y. H. Shen, S. H. Zhang, H. J. Li, Y. Ren, H. C. Liu, Chem.-Eur. J., 2010, 16, 7368-7371.

[4] S. S. Chen, P. Y. Qi, J. Chen, Y. Z. Yuan, RSC Adv., 2015, 5, 31566-31574.

[5] J. Y. Cai, H. Ma, J. J. Zhang, Z. T. Du, Y. Z. Huang, J. Gao, J. Xu, Chin. J. Catal., 2014, 35, 1653-1660.

[6] L. F. Gong, Y. Lu, Y. J. Ding, R. H. Lin, J. W. Li, W. D. Dong, T. Wang, W. M. Chen, Appl. Catal. A, 2010, 390, 119-126.

[7] Y. L. Wang, W. P. Deng, B. J. Wang, Q. H. Zhang, X. Y. Wan, Z. C. Tang, Y. Wang, C. Zhu, Z. X. Cao, G. C. Wang, H. L. Wan, Nat. Commun., 2013, 4, 2141.

[8] M. Dusselier, P. Van Wouwe, A. Dewaele, E. Makshina, B. F. Sels, Energy Environ. Sci., 2013, 6, 1415-1442. 


\title{
Graphical Abstract
}

Chin. J. Catal., 2016, 37: 502-509 doi: 10.1016/S1872-2067(15)61055-5

\section{Selective oxidation of glycerol to lactic acid over activated carbon supported Pt catalyst in alkaline solution}

Chen Zhang, Tao Wang *, Xiao Liu, Yunjie Ding*

Dalian Institute of Chemical Physics, Chinese Academy of Sciences; University of Chinese Academy of Sciences

$\mathrm{Pt} /$ activated carbon catalyst works efficiently for lactic acid production from glycerol under mild conditions. Different alkalis greatly influence both glycerol conversion and lactic acid selectivity, among which LiOH is optimal.

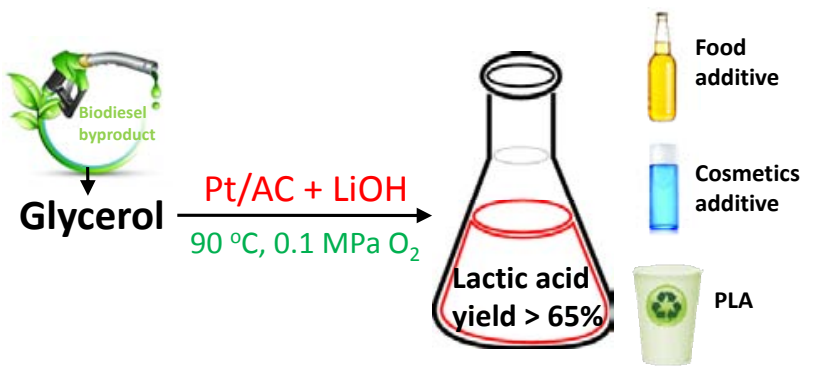

[9] R. P. John, K. M. Nampoothiri, A. Pandey, Appl. Microbiol. Biotechnol., 2007, 74, 524-534.

[10] H. Kishida, F. M. Jin, Z. Y. Zhou, T. Moriya, H. Enomoto, Chem. Lett., 2005, 34, 1560-1561.

[11] Z. Shen, F. M. Jin, Y. L. Zhang, B. Wu, A. Kishita, K. Tohji, H. Kishida, Ind. Eng. Chem. Res., 2009, 48, 8920-8925.

[12] L. S. Sharninghausen, J. Campos, M. G. Manas, R. H. Crabtree, Nat. Commun., 2014, 5, 5084.

[13] E. P. Maris, R. J. Davis, J. Catal., 2007, 249, 328-337.

[14] J. Feng, W. Xiong, B. Xu, W. D. Jiang, J. B. Wang, H. Chen, Catal. Commun., 2014, 46, 98-102.

[15] P. Lakshmanan, P. P. Upare, N. T. Le, Y. K. Hwang, D. W. Hwang, U. H. Lee, H. R. Kim, J. S. Chang, Appl. Catal. A, 2013, 468, 260-268.

[16] R. K. P. Purushothaman, J. van Haveren, D. S. van Es, I. Melián Cabrera, J. D. Meeldijk, H. J. Heeres, Appl. Catal. B, 2014, 147, 92-100.

[17] S. Chornaja, K. Dubencov, V. Kampars, O. Stepanova, S. Zhizhkun, V. Serga, L. Kulikova, React. Kinet., Mech. Catal., 2013, 108, 341-357.

[18] W. C. Ketchie, Y. L. Fang, M. S. Wong, M. Murayama, R. J. Davis, J. Catal., 2007, 250, 94-101.

[19] Y. Ryabenkova, P. J. Miedziak, N. F. Dummer, S. H. Taylor, N. Dimitratos, D. J. Willock, D. Bethell, D. W. Knight, G. J. Hutchings, Top. Catal., 2012, 55, 1283-1288.

[20] P. M. Sipos, G. Hefter, P. M. May, J. Chem. Eng. Data, 2000, 45, 613-617.

[21] W. Jin, H. Du, S. L. Zheng, H. B. Xu, Y. Zhang, J. Phys. Chem. B, 2010, $114,6542-6548$.
[22] D. Liang, J. Gao, J. H. Wang, P. Chen, Z. Y. Hou, X. M. Zheng, Catal. Commun., 2009, 10, 1586-1590.

[23] D. Wang, W. Q. Niu, M. H. Tan, M. B. Wu, X. J. Zheng, Y. P. Li, N. Tsubaki, ChemSusChem, 2014, 7, 1398-1406.

[24] S. E. Davis, M. S. Ide, R. J. Davis, Green Chem., 2013, 15, 17-45.

[25] S. S. Liu, K. Q. Sun, B. Q. Xu, ACS Catal., 2014, 4, 2226-2230.

[26] D. Liang, J. Gao, H. Sun, P. Chen, Z. Y. Hou, X. M. Zheng, Appl. Catal. $B, \mathbf{2 0 1 1}, 106,423-432$.

[27] S. Lux, M. Siebenhofer, Catal. Sci. Technol., 2013, 3, 1380-1385.

[28] C. B. Rasrendra, B. A. Fachri, I. G. B. N. Makertihartha, S. Adisasmito, H. J. Heeres, ChemSusChem, 2011, 4, 768-777.

[29] H. Kishida, F. M. Jin, X. Y. Yan, T. Moriya, H. Enomoto, Carbohydr. Res., 2006, 341, 2619-2623.

[30] G. L. Lookhart, M. S. Feather, Carbohydr. Res., 1978, 60, 259-265.

[31] D. R. Lide, W. M. Haynes, G. Baysinger, L. I. Berger, M. Frenkel, R. N. Goldberg, CRC Handbook of Chemistry and Physics, vol. 8, 90th (CD-ROM Version) ed., CRC Press/Taylor and Francis, Boca Raton, FL, 2010.

[32] R. D. Shannon, Acta Crystallogr., Sect. A, 1976, 32, 751-767.

[33] R. Battino, T. R. Rettich, T. Tominaga, J. Phys. Chem. Ref. Data, 1983, 12, 163-178.

[34] B. N. Zope, D. D. Hibbitts, M. Neurock, R. J. Davis, Science, 2010 $330,74-78$

[35] K. E. Gubbins, R. D. Walker Jr, J. Electrochem. Soc., 1965, 112, 469-471.

[36] N. Worz, A. Brandner, P. Claus, J. Phys. Chem. C, 2010, 114, 1164-1172.

[37] T. Mallat, A. Baiker, Chem. Rev., 2004, 104, 3037-3058.

\section{活性炭担载的铂催化剂在碱性条件下选择性氧化甘油制备乳酸}

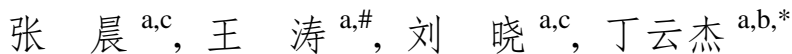 \\ a中国科学院大连化学物理研究所洁净能源国家实验室 (筹), 辽宁大连 116023 \\ b 中国科学院大连化学物理研究所催化基础国家重点实验室, 辽宁大连 116023 \\ c中国科学院大学, 北京 100049
}

摘要: 生物柴油是一种环境友好的燃料, 随着其生产及应用的快速增长, 其生产过程中重要的副产物甘油将会大量过剩. 因此, 将甘油转化为高附加值的化学品对于提高生物柴油整体竞争力具有重大意义. 乳酸是重要的化工原料, 可用于制备 生物兼容和可降解的聚乳酸塑料, 广泛应用于食品和医药等领域. 近年来, 由甘油制乳酸的研究受到格外关注, 相对于水 热反应和氢解反应等, 催化选择氧化反应因温和的反应条件而更具竞争力.

目前, 甘油催化选择氧化制乳酸一般需加入较高比例的 $\mathrm{NaOH}$, 而碱的类型对反应性能的影响鲜有报道. 另外, 催化剂 
常采用 $\mathrm{TiO}_{2}$ 和 $\mathrm{CeO}_{2}$ 等氧化物载体, 而炭载体具有比表面积较大、在酸碱溶液中稳定及贵金属易于回收等优点, 在催化领域 有着广泛应用. 因此, 本文研究了活性炭(AC)担载的 Pt 催化剂在甘油催化选择氧化制乳酸反应中的催化性能.

首先研究了 Pt/AC 催化剂和碱在甘油催化选择氧化制乳酸过程中的催化作用. 实验发现, $\mathrm{Pt} / \mathrm{AC}$ 和碱协同作用才能得 到乳酸. Pt/AC 催化剂在甘油脱氢生成中间产物 (甘油醛和二羟基丙酮) 的过程中起主导作用, 碱的存在能够促进甘油羟基 脱氢; 中间产物实验证实, 中间产物生成乳酸过程中碱起主导作用, 它促进甘油醛和二羟基丙酮脱水反应和坎尼扎罗重排 反应获得乳酸. 进一步研究发现, 中间产物二羟基丙酮比甘油醛更有利于乳酸生成, 而 $\mathrm{Pt} / \mathrm{AC}$ 催化剂有利于中间产物氧化 为甘油酸.

进一步研究了不同类型的碱对反应性能的影响. 结果表明, 碱金属氢氧化物 (LiOH, NaOH, KOH) 比碱土金属氢氧化 物 $\left(\mathrm{Ba}(\mathrm{OH})_{2}\right)$ 更有利于提高甘油转化率和乳酸选择性. 在加入碱金属氢氧化物条件下, 甘油转化率与其离子半径呈正相关, 而乳酸选择性则呈相反趋势. 在 $\mathrm{LiOH}$ 存在下, 乳酸选择性明显高于 $\mathrm{NaOH}$ 和 $\mathrm{KOH}$ 条件. 当 $\mathrm{LiOH}$ :甘油摩尔比为 1.5 时, 甘油转化率和乳酸选择性均最高. 在较低的 $\mathrm{LiOH}$ 与甘油摩尔比时, 随着反应的消耗, 溶液中的 $\mathrm{OH}^{-}$减少, 其促进甘油脱氢 的作用变弱, 并且不利于中间产物进行坎尼扎罗反应, 故反应活性和乳酸选择性较差; 而当 LiOH 比例过高时, 会导致溶解 氧浓度迅速降低, 从而使甘油转化率和乳酸选择性下降, 同时副产物甘油酸的选择性有所提高. 这可能是因为较高比例的 碱会促进中间产物甘油醛生成, 该中间产物在 Pt/AC 催化作用下发生进一步氧化反应生成甘油酸.

研究了反应时间对催化性能的影响. 结果表明, 反应 $6 \mathrm{~h}$ 后, 甘油已经完全转化, 乳酸选择性最高, 达到 69.3\%; 进一步 延长反应时间, 乳酸选择性有所下降, 而副产物乙酸选择性略有增加, 这可能是部分乳酸分解所致. Pt/AC 催化剂经5次循 环使用后仍保持了较高的甘油转化率和乳酸选择性.

关键词: 甘油; 乳酸; 铂; 活性炭; 氧化; 碱的类型

收稿日期: 2016-01-06. 接受日期: 2016-01-30. 出版日期: 2016-04-05.

*通讯联系人. 电话/传真: (0411)84379143; 电子信箱: dyj@dicp.ac.cn

\#通讯联系人. 电话/传真: (0411)84379143; 电子信箱: wangtao@dicp.ac.cn

基金来源：国家自然科学基金 (21176236).

本文的英文电子版由Elsevier出版社在ScienceDirect上出版(http://www.sciencedirect.com/science/journal/18722067). 